\title{
Leadership Orientation as Mediator of Organizational Culture Effects on School Leadership
}

\author{
Burhanuddin \\ Department of Educational Administration \\ State University of Malang, Indonesia \\ burhanuddin.fip@um.ac.id
}

\author{
Achmad Supriyanto \\ Department of Educational Administration \\ State University of Malang, Indonesia \\ a.supriyanto@um.ac.id
}

\author{
Eka Pramono Adi \\ Department of Curriculum and Educational Technology \\ State University of Malang, Indonesia \\ eka.pramono.fip@um.ac.id
}

\begin{abstract}
School leadership is predicted to be influenced by organization culture. However this claim can be argued for such a connection is potentially determined by the way people to be led. This study was aimed to investigate the influences of organizational culture on leadership, and how leadership orientations mediate this relationship. The study was conducted employing quantitative approach with a multiple regression design. Findings indicate the types of organizational cultures had indirect effects of leadership performance. These were mediated by leadership orientations implemented in school organizations. School leaders, then, need to explore how leadership models are compatible with the contexts where particular types of culture may exist. Other studies are expected to relate this research focus with different variables in order to produce more comprehensive conclusions.
\end{abstract}

Keywords: organizational culture, school leadership, leadership performance

\section{INTRODUCTION}

School as an organization is perceived to be influenced by organizational situation. This includes the types of organizational culture that may be rooted in the school environment. These subsequently impact the way school leaders work with their members and employ appropriate leadership styles or orientations [1, 2]. Evidence from previous studies and literature explain that the effectiveness of leadership in most organizations is determined by leaders' behaviour and capacities to choose and implement the proper orientations.

To develop the framework of this study, overview of organizational culture, leadership orientation, and effects of organizational culture on leadership performance are discussed. The investigation was guided by three research questions: (1) does organizational culture influence school leadership effectiveness? (2) do leadership orientations (people oriented \& task oriented) influence school leadership performance? and (3) are effects of organizational culture types on school leadership mediated by leadership orientations?

\section{THEORETICAL FRAMEWORK}

\section{Overview of Organizational Culture}

Organizational culture as a part of situation is regarded having certain impacts on leadership performance. This term is defined in many literature as sharing among members on values, belief, norm, assumptions, and routinity. These are brought into the workplace, adopted, and kept by members [3, 4]. The embedded values of culture guide behaviour and consolidate individual efforts to work cooperatively to achieve organizational goals and objectives [2, 5-8]. This term is also known as corporate culture. It refers to an acknowledgement of different members behaviours and how they work in handling jobs [9]. Bartol et. al. [10] also explain elements of organization culture connecting members within an organization. School as organization has cultural dimensions manifested into four levels including values, artefact, assumptions, and perspectives [11, 12]. The construct of organizational culture as found in studies and experienced in public organizations comprise of several types of organizational culture. These are known as bureaucratic, supportive, clan, adhocracy, market, and innovative $[3,7,9,13,14]$.

The bureaucratic model concerns more on rule of work, standard, reliability, predictability, and efficiency. Supportive on the other hand put attention on harmony and worm relations among people, subtleness, friendly, openness, trust, security, fairness, and mutual understanding of individuals (Wallach, 1983). Clan organization is described by Cameron \& Quinn [15] where members are treated as a part of family. Teamwork, participation, empowerment, cohesiveness, and corporate commitment portray the way leaders and followers work together. Adhocracy provides a dynamic environment at work where people are creative, dynamic, innovative, and employ entrepreneurial programs and the opportunities. Market oriented model value higher productivity for members, corporate benefits, market penetration, and competition. Finally, leaders in innovative environment encourage their members to pursue higher achievements with strong motivation and morale. This type has similarities with market orientated organizations.

Those types of culture are predicted to characterizing a school organization, and automatically differentiate one school compared to other schools. This phenomenon consequently becomes a challenging issue that will be experienced by educational leaders 
especially principals who work within the complex school organization system. Principals as leaders, then, have to be familiar with the school context and its embedded culture $[13,16,17]$. The dynamic situational factor of culture that must be considered in selecting and implementing sorts of leadership approaches appropriately [3] - to ensure the achievement of higher leadership performance within the school organization $[18,19]$.

\section{Leadership Orientations}

Research in leadership identified various models of leadership that can be used at organizations including schools. For the purpose of study, two models are introduced including "people oriented" and "task oriented". These were initially developed as leadership orientations by Fiedler [20] in his Contingency theory of leadership. Leaders who choose task oriented type concern more on work targets that must be accomplished by workers, keeping on schedule and deadline, and efficiency in handling related activities. As followers, they are controlled and monitored regularly to ensure the completion of tasks assigned to each individual, group, and unit. Contingency theory views effectiveness of the orientations depends on individual and organizational condition when those are implemented.

\section{Effects of Organizational Culture on Leadership Performance}

Previous research findings and literature conclude that organizational culture as part of situation influence school leadership effectiveness [21]. This proposition is in line with leadership dependency on situation [3, 22, 23]. Culture and the way how leaders behave in school organization will have subsequent impacts on academic student achievement and their performance. This also determine teachers behaviour and the quality of professional development program at the school system [1].

However, connections between culture and its dependent factors are not a simple model. Effects of particular organization cultures are potentially mediated by leadership models or orientations employed by leaders as well as the principals. To conclude, these influence school leadership performance, but they may have only indirect effects on leadership performance. In order to implement leadership strategies successfully, principals have to adjust their style of leadership with the situation they encounter, explore various leadership models and choose and employ the appropriate one. [13, 16, 17].

Based on this theoretical overview, two hypotheses are proposed: (Hol) organizational cultures (bureaucratic, supportive, market, clan, adhocracy, innovative) do not have direct effects on any leadership orientations (people oriented \& task oriented); (Ho2) effects of organizational cultures on leadership performance are not mediated by any leadership orientations: people and task oriented model; (Ho3) leadership orientations do not have direct effects on school leadership performance.

\section{METHODS}

The study was conducted employing quantitative approach with a multiple regression design. The study involved 220 primary school teachers in the City of Malang Indonesia. Purposive sampling method was used to select these sample members consisting of 71 male and 149 female. A set of survey questionnaire was developed to measure the observed variables. This was structured from 115 items on a five point Likert scale, and grouped into four measurement scales: organizational culture (40 items), leadership (40 items), organization situation (15 items), and leadership orientation (20 items). Sample items of the scales are: "jobs are highly structured" and "school has successfully publicized vision and mission statements to the public". Internal consistency test was run that result in higher alpha coefficients for all items in each scale in the range of $\alpha=0.70-0.91$. Effects of independent variables on dependent variables were computed using path analysis method.

\section{RESULTS}

In line with the main purpose of this study, data in this section is delivered to find out whether types of organizational culture (bureaucratic, supportive, market, clan, adhocracy, innovative) simultaneously influence school leadership performance. Three research questions were raised in generating the research findings: (1) does organizational culture influence school leadership effectiveness? (2) do leadership orientations (people oriented \& task oriented) significantly influence school leadership performance? and (3) are effects of organizational culture types on school leadership mediated by leadership orientations? In order to reveal responses to the two research questions, hypotheses were proposed including (Hol) The types of organizational culture (bureaucratic, supportive, market, clan, adhocracy, innovative) do not have direct effects on any leadership orientations (people oriented \& task oriented); (Ho2) effects of organizational cultures on school leadership performance are not mediated by any leadership orientations: people and task oriented model; (Ho3) leadership orientations do not have direct effects on school leadership performance.

To test the proposed hypotheses, a theoretical model in Figure 1 was developed to measure organization culture effects on leadership orientation and leadership performance. Factor scores for each variable were retrieved using principal components analysis.

Results of the analysis for the initial path model are presented in Table 1. Some estimates are retrieved with $\mathrm{p}$ values, $>0.05$, or not significant. The findings, thus, indicate not all organizational culture components had significant effects on leadership performance. For the purpose of interpretations, strength of the effects as represented by values for each coefficient can be interpreted using effect size classifications: (1) small $(\beta=0.02)$, (2) medium $(\beta=$ $0.15)$, and (3) large $(\beta=0.35)$. 


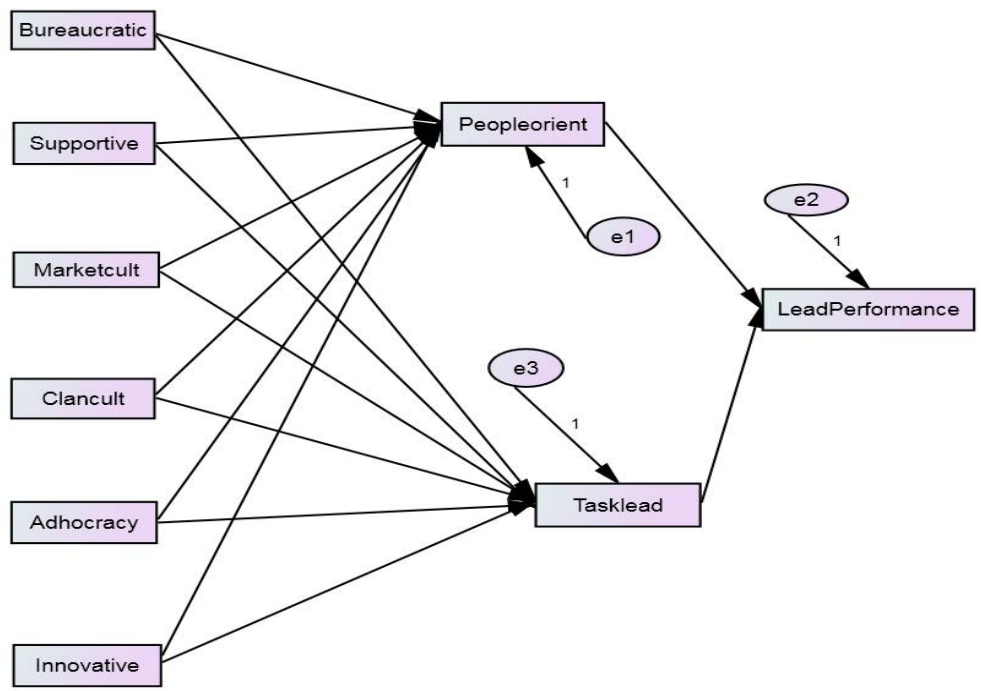

Figure 1

The Hypothesized Path Model of Organizational Culture Effects on Leadership Orientations and Leadership Performance

Table 1

Regression Weights of the Initial Structure

\begin{tabular}{|l|c|l|r|r|r|l|}
\hline \multicolumn{1}{|c|}{ Criterion } & & \multicolumn{1}{c|}{ Predictor } & Estimate & S.E. & C.R. & P \\
\hline Peopleoriented & $<---$ & Support & .280 & .053 & 5.256 & $* * *$ \\
\hline Peopleoriented & $<---$ & Market & .118 & .053 & 2.219 & .026 \\
\hline Taskoriented & $<---$ & Innov & .155 & .056 & 2.773 & .006 \\
\hline Taskoriented & $<---$ & Clan & -.116 & .056 & -2.083 & .037 \\
\hline Taskoriented & $<---$ & Support & .145 & .056 & 2.595 & .009 \\
\hline Taskoriented & $<---$ & Market & .192 & .056 & 3.446 & $* * *$ \\
\hline Taskoriented & $<---$ & Burueauc & .379 & .056 & 6.793 & $* * *$ \\
\hline Peopleoriented & $<---$ & Innov & .331 & .053 & 6.208 & $* * *$ \\
\hline Peopleoriented & $<---$ & Burueauc & .029 & .053 & .540 & .589 \\
\hline Taskoriented & $<---$ & Adhoc & -.047 & .056 & -.842 & .400 \\
\hline Peopleoriented & $<---$ & Clan & -.008 & .053 & -.143 & .886 \\
\hline Peopleoriented & $<---$ & Adhoc & -.005 & .053 & -.101 & .919 \\
\hline LeadPerform & $<---$ & Peopleoriented & .444 & .050 & 8.891 & $* * *$ \\
\hline LeadPerform & $<---$ & Taskoriented & .421 & .047 & 8.917 & $* * *$ \\
\hline
\end{tabular}

Based on this guideline, as shown in the table, components of the organizational cultures only influence indirectly on leadership performance. Their effects are mediated by two of leadership orientations: people oriented and task oriented styles. However, there are several predictors that provide small, negative, and insignificant effects. These include variables "Clan" on "Taskoriented" with estimate values of $\beta=(-.116), p=0.037$ (> 0.01); "Burueauc" on "Peopleoriented" with estimate values of $\beta=0.029$, $p=0.589$ (> 0.01) "Adhoc" on "Taskoriented", $\beta=(-$ $.047), p=0.400$ (> 0.01); "Clan" on "Peopleoriented", $\beta=$ (-.008), $p=>0.01$; "Adhoc" on "Peopleoriented", $\beta=-.005), p=0.919(>0.01)$.

Since the estimates of the relationship of some latent variables and their predictor effects are not significant, the second model was proposed as shown in Figure 2. Compared with the first or initial path, some modifications were made in the second model. Both latent variables of "Bureaucratic" and "Clan" were only connected to one leadership orientation, that is "Tasklead" and variable. While two arrows connecting "Adhocracy" to any other variables were removed.

Findings generated from this modified model were reported in Table 2. Results indicate the rest of predictors had significant direct effects on their criterion variables of leadership orientations and their indirect effects on school leadership performance. Table 3 also listed standardized coefficients of predictors in the modified model. All estimates are significant. This finding provide strong evidence that with the exception "adhocracy", other types of organizational cultures (bureaucratic, supportive, market, clan, innovative) had relationships and with leadership orientation and its performance. 
Since the $p$ values obtained are less than 0.05 , the null hypothesis $(\mathrm{Hol})$ of this study that "the types of organizational culture (bureaucratic, supportive, market, clan, adhocracy, innovative) do not have direct effects on each of leadership orientations (people oriented \& task oriented)" is partly rejected. In other words, with the exception of "adhocracy" type, all the organizational culture types (bureaucratic, supportive, market, clan, adhocracy, innovative) had direct effects on both leadership orientations (people oriented and task oriented).

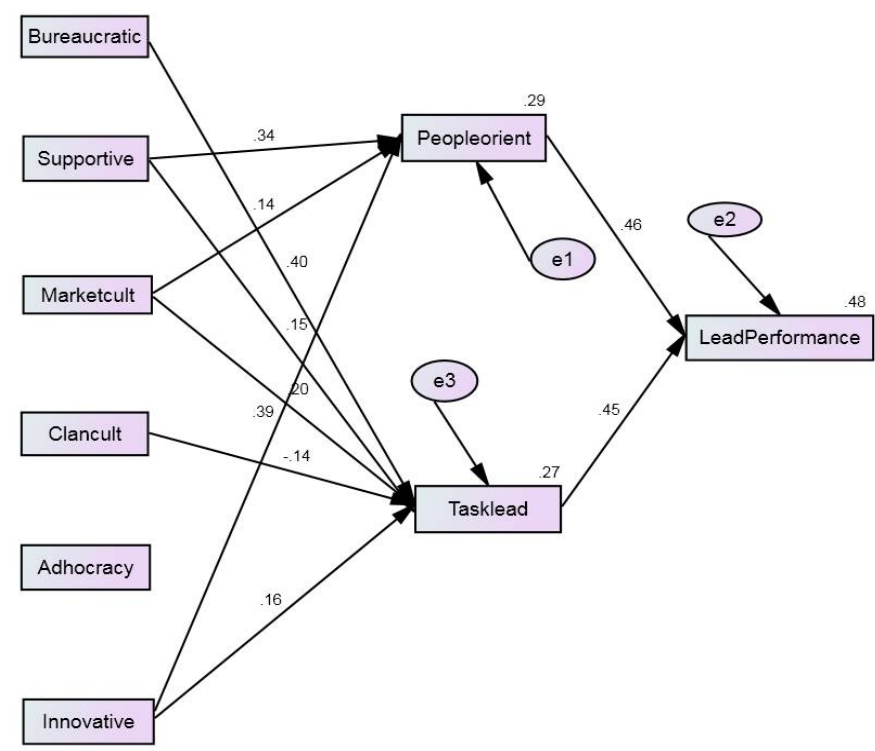

Figure 2

The Second Model of Organizational Culture

Effects on Leadership Orientations and Leadership Performance

Table 2

Regression Weights of the Modified Model

\begin{tabular}{|c|c|c|c|c|c|c|}
\hline \multicolumn{7}{|c|}{ 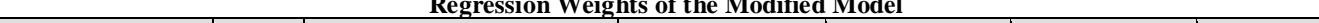 } \\
\hline Criterion & & Predictors & Estimate & S.E. & C.R. & $\mathbf{P}$ \\
\hline Peopleoriented & $<---$ & Support & .305 & .053 & 5.732 & *** \\
\hline Peopleoriented & $\begin{array}{l}<-- \\
\end{array}$ & Market & .129 & .053 & 2.419 & .016 \\
\hline Taskoriented & $<--$ & Innov & .145 & .056 & 2.595 & .009 \\
\hline Taskoriented & $<--$ & Clan & -.127 & .056 & -2.270 & .023 \\
\hline Taskoriented & $<--$ & Support & .142 & .056 & 2.550 & .011 \\
\hline Taskoriented & $<--$ & Market & .189 & .056 & 3.384 & $* * *$ \\
\hline Taskoriented & <--- & Burueauc & .373 & .056 & 6.687 & **** \\
\hline Peopleoriented & <--- & Innov & .346 & .053 & 6.507 & **** \\
\hline LeadPerform & $<--$ & Peopleoriented & .444 & .049 & 9.057 & *** \\
\hline LeadPerform & $<--$ & Taskoriented & .421 & .047 & 8.889 & $* * *$ \\
\hline
\end{tabular}

On the other hand, such a finding also successfully rejected the null hypothesis (Ho2) that "effects of types of organizational cultures on leadership performance are not mediated by the two leadership orientations: people and task oriented model". Thus, it can be claimed that the influences of types of organizational culture on leadership are mediated by leadership orientations: people and task oriented model.

As illustrated in Figure 2, components of organizational cultures have significant effects on both leadership orientations and leadership performance. This also explains the types of cultures in the modified path had direct effects on the two leadership orientations. On the other hand their effects on school leadership performance were mediated by the leadership orientations: People oriented and task oriented leadership.

But, as indicated in the second path model, there is still one predictor that had a very small and negative effect or relationship. This involve an effect of "clan" on "Taskoriented" with an estimate (-.127) or in the standardized coefficient listed in Table 3 is (-.136), $p=0.023$. To improve the model, the final path was structured as shown in Figure 3. Estimates obtained through this final model are significant.

These are listed in Table 4. Effect sizes of predictor variables on their criterion variables are 
bigger. Those are indicated by higher standardized regression weights obtained in the path analysis results as recorded in Table 5 for this final model. Both arrows from leadership orientations leading to performance provide large effect size. This finding demonstrate significant and strong effects of people oriented $(\beta=$
$0.47)$ and task oriented $(\beta=0.45)$ on leadership performance. Thus, $\mathrm{Ho} 3$, that leadership orientations do not have direct effects on school leadership performance is rejected. This study, then, find that the two leadership orientations had strong effects on leadership performance.

Table 3

Standardized Regression Weights of the Modified Model

\begin{tabular}{|l|c|l|r|}
\hline \multicolumn{1}{|c|}{ Criterion } & & \multicolumn{1}{c|}{ Predictor } & Estimate \\
\hline Peopleoriented & $<---$ & Support & .340 \\
\hline Peopleoriented & $<---$ & Market & .144 \\
\hline Taskoriented & $<---$ & Innov & .156 \\
\hline Taskoriented & $<---$ & Clan & -.136 \\
\hline Taskoriented & $<---$ & Support & .153 \\
\hline Taskoriented & $<---$ & Market & .203 \\
\hline Taskoriented & $<---$ & Burueauc & .401 \\
\hline Peopleoriented & $<---$ & Innov & .386 \\
\hline LeadPerform & $<---$ & Peopleoriented & .463 \\
\hline LeadPerform & $<---$ & Taskoriented & .454 \\
\hline
\end{tabular}

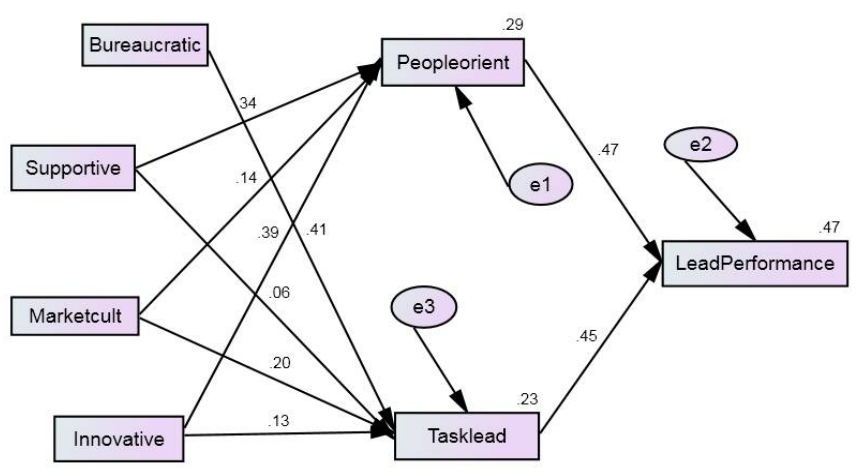

Figure 3

The Final Model of Organizational Culture Effects on Leadership Orientations and Leadership Performance

Table 4

Regression Weights of the Final Model

\begin{tabular}{lclrrrr}
\multicolumn{7}{c}{ Regression Weights of the Final Model } \\
\hline & & & Estimate & S.E. & C.R. & P \\
\hline Peopleoriented & $<---$ & Support & .305 & .053 & 5.732 & *** \\
Peopleoriented & $<---$ & Market & .129 & .053 & 2.419 & .016 \\
Taskoriented & $<---$ & Innov & .121 & .056 & 2.164 & .030 \\
Taskoriented & $<---$ & Support & .058 & .056 & 1.043 & .297 \\
Taskoriented & $<---$ & Market & .186 & .056 & 3.326 & $* * *$ \\
Taskoriented & $<---$ & Burueauc & .370 & .056 & 6.611 & *** \\
Peopleoriented & $<---$ & Innov & .346 & .053 & 6.507 & *** \\
LeadPerform & $<---$ & Peopleoriented & .444 & .049 & 9.101 & *** \\
LeadPerform & $<---$ & Taskoriented & .421 & .048 & 8.740 & *** \\
\hline
\end{tabular}

Begin with the organization culture effects on the two leadership orientations as the dependent or criterion variables, in detail the effect sizes performed by the associations among latent variables are summarized in Table 5. In referring to the classification of the effect sizes that has been defined in this study, "bureaucratic" type of organizational culture obtained the strongest effect on its criterion variable "task oriented leadership". This is indicated by a larger effect size of $\beta=0.370(\beta,>0.35)$. This is followed by the other predictors that on average provided medium effect sizes $(\beta,>0.15)$. These include "supportive" effect on "people oriented" leadership style $(\beta=$ $0.305)$; "market" organizational culture on "task oriented" leadership $(\beta=0.186)$; "market" on "people oriented style $(\beta=0.129)$; "Innovative" organization culture on "task oriented leadership style $(\beta=0.121)$. The last predictor with the smallest coefficient was obtained by the effect of "supportive" culture on "task oriented leadership" ( $\beta=0.58)$. 
Table 5

Standardized Regression Weights of the Final Model

\begin{tabular}{|l|c|l|r|}
\hline & & & Estimate \\
\hline Peopleoriented & $<---$ & Support & .340 \\
\hline Peopleoriented & $<---$ & Market & .144 \\
\hline Taskoriented & $<---$ & Innov & .133 \\
\hline Taskoriented & $<---$ & Support & .064 \\
\hline Taskoriented & $<---$ & Market & .205 \\
\hline Taskoriented & $<---$ & Burueauc & .407 \\
\hline Peopleoriented & $<---$ & Innov & .386 \\
\hline LeadPerform & $<---$ & Peopleoriented & .469 \\
\hline LeadPerform & $<---$ & Taskoriented & .450 \\
\hline
\end{tabular}

To summarize, the values retrieved from this final model that listed in Table 5 demonstrate strong evidence for the findings in explaining the both relationships among latent variables, and significant and strong effects of the predictors on their respective criterion variables investigated in this study.

\section{DISCUSSION}

Evidence from the measurement development indicated the scales have obtained accepted indicators as reliable and valid instruments since items had higher alpha coefficients and high loadings for the scales [24]. The data were, then, can be used further to discuss the research findings. The discussions in this section are driven in referring to the research questions developed in this study: (1) does organizational culture influence school leadership effectiveness? (2) do leadership orientations (people oriented \& task oriented) influence school leadership performance? and (3) are effects of organizational culture types on school leadership mediated by leadership orientations? Hypotheses have been proposed as the base for the analysis and interpretations.

Leadership performance within school systems are regarded to be influenced by the types of organizational culture employed by school leaders in particular principals. However this proposition was argued by many researchers in studies since effects of the culture are still determined by the way how school leaders lead their school organization [21] and the context when then leadership styles or orientations are implemented [22].

Three path models were developed to test the hypotheses for the multiple relationships among factors and predictor effects on criterion variables. Findings in the first model result in estimate values for the effects of culture on leadership performance as dependent or criterion variables. Results showed organizational culture had indirect effects of leadership. But not all predictors provided significant effects. The second model, thus, was initiated by including the paths that had significant regression weights. It provided strong evidence that in general the organizational culture had relationship with leadership orientations (both task and people oriented style) and lead to the increased school leadership performance.

The first hypothesis (Hol), "the types of organizational culture do not have direct effects on each of leadership orientations" is then rejected. It means that organizational culture can be concluded as having significant impact on leadership orientations. Coefficient regression weights in the second or modified model also contributed to the rejection of hypothesis (Ho2) that "effects of types of organizational cultures on leadership performance are not mediated by the two leadership orientations: people and task oriented model". It can be explained that both leadership orientations (people and task oriented) mediate the influences of types of organizational culture on leadership. All these findings are in line with propositions of previous studies and literature $[3,13$, 23].

Since in the second model, effect of "clan culture" on "task oriented" had a very small estimate, the model, was then refined in the third path model. This becomes a final path model that successfully provided significant and positive coefficients on their criterion variables. The model demonstrated strong effects of both "people oriented" and task oriented" on school leadership performance. These lead to the rejection of (Ho3): "leadership orientations do not have direct effects on school leadership performance is rejected". The interpretation is the two leadership orientations had direct and strong effects on leadership performance. Such a finding is relevant with other studies and literature or as suggested by $[3,13,16]$.

\section{CONCLUSION}

In conclusion the types of organizational culture as well as those had significant effects (bureaucratic, supportive, market culture, innovative) influenced school leadership effectiveness. Both leadership orientations in term of people oriented and task oriented had significant and direct effects on school leadership performance.

Finally, effects of these types of organizational culture on school leadership were mediated by the implementation of task and people leadership models. The findings contribute to the theory and principles of management and leadership in improving school organizational performance. To pursue more comprehensive findings and conclusions, future research is suggested to investigate this study area involving other institutions as the target sample. 


\section{REFERENCES}

1. Kruger, M.L., B. Witziers, and P. Sleegers, The impact of school leadership on school level factors: validation of a causal model. School Effectiveness and School Improvement, 2007. 18(1): p. 1-20.

2. Yukl, G.A., Leadership in organizations 5th ed. 2002, Upper Saddle River, N.J: Prentice-Hall International Inc.

3. Schein, E.H., Organizational culture and leadership (4th ed). 2010, San Francisco, CA: Jossey-Bass.

4. Ployhart, R.E., D. Hale-Jr, and M.C. Campion, Staffing Within the Social Context, in The Oxford handbook of organizational climate and culture, P.E. Nathan, Editor. 2014, Oxford University Press: New York.

5. Jones, G.R. and J.M. George, Contemporary management. 4th ed. 2006, Boston: McGraw-Hill.

6. Gibson, J.L., et al., Organizations: Behavior, structure, processes 12th ed. 2006, Boston: Boston: McGrawHill/Irwin.

7. Lok, P. and J. Crawford, The effect of organizational culture and leadership style on job satisfaction and organisational commitment: a cross-national comparation. Journal of Management Development, 2004. 23(4): p. 321-338.

8. Champoux, J.E., Organizational behavior: Essential tenets 2nd ed. 2003, Australia: Thompson SouthWestern.

9. Wallach, E.J., Individuals and organizations: The cultural match. Training and Development Journal, 1983. 37(2): p. 28-36.

10. Bartol, K., et al., Management: A Pacific rim focus. 3rd ed. 2002, Roseville NSW 2069, Australia: The McGraw Hill-Company Australia Pty Limited.

11. Sergiovanni, T.J., The principalship: A reflective practice perpective. 1991, Boston: Allyn and Bacon, Inc.

12. Sergiovanni, T.J., The principalship: a reflective practice perspective. 1987, Boston: Allyn and Bacon, Inc.

13. Ferreira, A.I. and M.M. Hill, Organisational cultures in public and private Portuguese Universities: A case study High Educ 2008. 55: p. 637-650.

14. Cameron, K.S. and R.E. Quinn, Diagnosing and changing organizational culture: Based on the competing values framework. 3rd ed. 2011, San Francisco, CA: JOSSEY-BASS

15. Cameron, K.S. and R.E. Quinn, Diagnosing and changing organizational culture: based on the competing values framework. 2006: Jossey-Bass.

16. Robinson, V.M.J., C.A. Lloyd, and K.J. Rowe, The impact of leadership on student outcomes: an analysis of the differential effects of leadership types. Educational Administration Quarterly, 2008. 44(5): p. 635-674.

17. Datnow, A. and M.E. Castellano, Managing and guding school reform: leadership in success for all schools. Educational Administration Quarterly, 2001. 37(2): p. 219-249.

18. Somech, A. and M. Wenderow, The impact of participative and directive leadership on teachers' performance: The intervening effects of job structuring, decision domain, and leader-member exchange. Educational Administration Quarterly, 2006. 42(5): p. 746-772.

19. Wiyono, B.B., The effect of self-evaluation on the principals' transformational leadership, teachers' work motivation, teamwork effectiveness, and school improvement. International Journal of Leadership in Education, 2017: p. 1-21.
20. Fiedler, F.E., Leadership effectiveness. American Behavioral Scientist, 1981. 24(5): p. 619-632.

21. Bush, T. and D. Middlewood, Leading and managing people in education. 2005, London: Sage Publications.

22. Yukl, G.A., Leadership in organizations. 7 ed. 2010 Upper Saddle River, N.J: : Prentice-Hall International Inc.

23. McKee, A., T. Kemp, and G. Spence, Management: $a$ focus on leaders. 2013, Frenchs Forest NSW: Pearson.

24. Cohen, L., L. Manion, and K. Morrison, Research Methods in Education. 2018, New York: Routledge. 